\title{
Relations of Japanese Investment Styles and US Investment Styles after the Lehman Bankruptcy: Evidence from Japanese and US Stock Markets
}

\author{
Chikashi Tsuji ${ }^{1{ }^{*}}$ \\ ${ }^{1}$ Faculty of Economics, Chuo University, Tokyo, Japan \\ *Correspondence: Faculty of Economics, Chuo University. 742-1 Higashinakano, Hachioji-shi, Tokyo 192-0393, \\ Japan. Tel: 81-42-674-2211.E-mail: mail_sec_low@minos.ocn.ne.jp
}

Received: April 11, 2016

Accepted: June 9, $2016 \quad$ Online Published: June 14, 2016

doi:10.5430/wjss.v3n2p42

URL: http://dx.doi.org/10.5430/wjss.v3n2p42

\begin{abstract}
In this paper, in order to clarify the stock return relations of Japanese investment styles and US investment styles after the Lehman bankruptcy, we investigate the dynamic return linkages of Japanese four kinds of stock indices and US three kinds of stock indices. Specifically, this study empirically inspects the dynamic effects of the Nikkei 225, Tokyo stock price index (TOPIX), and the Morgan Stanley Capital International (MSCI) Japanese value- and growth-style equity indices on the MSCI US value, growth, and standard equity indices. As analyzing methodology, we employ the threshold generalized autoregressive conditional heteroskedasticity (TGARCH) model, and as a result of our investigations, we obtain clear and consistent important findings as follows. (1) First, our examinations by the TGARCH model evidence that the Nikkei 225 and TOPIX have a stronger effect on the MSCI US standard stock index than on the MSCI US value- and growth-style indices. (2) Second, our explorations by the TGARCH model further reveal that the time-series evolution of the MSCI Japanese value- and growth-style indices also has a stronger effect on the MSCI US standard stock index than on the MSCI US value- and growth-style stock indices.
\end{abstract}

Keywords: growth equity index, international stock market linkage, investment style, TGARCH model, value equity index

\section{Introduction}

The international stock market interdependence (e.g., Voronkova, 2004; Wälti, 2011; el Alaoui et al., 2015) and the value and growth effects on stock performances (e.g., Ding et al., 2005; Fama and French, 2007; Abhyankar et al., 2009; Huang, 2011) have been paid much attention by the researchers in the fields of business, economics, management, and finance. However, we point out that these two appealing topics have been separately studied. Thus, in order to step forward into new research area, using multiple daily time-series stock return data of US and Japanese value, growth, and standard equity indices, this paper attempts to conduct new research by combining these two issues.

More specifically, our objective is to empirically inspect the effects of the Nikkei 225 (hereinafter called 'the Nikkei'), Tokyo stock price index (hereinafter called 'TOPIX'), and the Morgan Stanley Capital International (MSCI) Japanese value- and growth-style equity indices on the MSCI value, growth, and standard equity indices of the United States. This study focuses on the period after the Lehman bankruptcy; and by this, we aim to clarify the stock return relations of Japanese investment styles and US investment styles after the Lehman shock in the US. As analyzing methodology, we employ the threshold generalized autoregressive conditional heteroskedasticity (TGARCH) model in this research.

Briefly documenting our new findings, first, our investigations reveal that (1) after the Lehman bankruptcy in the US, the Nikkei and TOPIX have a stronger effect on the MSCI US standard stock index than on the MSCI US value- and growth-style indices. Second, we find that (2) after the Lehman shock in the US, the time-series evolution of the MSCI Japanese value- and growth-style indices also has a stronger effect on the US standard stock index than on the MSCI US value- and growth-style stock indices.

The remainder of the article is structured as below. First, Section 2 conducts a literature review. Next, Section 3 
documents our data and Section 4 explains the econometric methodology employed in this paper. Further, Section 5 reports our empirical results and finally, Section 6 concludes the paper.

\section{Literature Review}

We here concisely review existing literature in this section. As regards the research of international stock market interdependence, there are many past studies; however, those papers examined the simple linkages among standard equity indices. Reviewing by focusing on very recent papers, Liu (2013) analyzed the international equity market interdependence by using the standard stock market indices as to 40 world markets. Gupta and Guidi (2012) examined the time-varying co-movements and cointegration relations among Indian and Asian developed stock markets. Graham et al. (2013) investigated not only global but also regional co-movements of the Middle East and North Africa (MENA) stock markets. On the other hand, with respect to the research of the value and growth stocks, value effects were much more studied than growth effects. More concretely, Black et al. (2007) investigated the long-run relations among the indices of the value premiums as to G7 countries. Moreover, employing equity return data in international markets, Fama and French (2012) investigated the momentum, value, and size effects in the world stock markets.

In contrast to the value effects, there are very few papers that analyzed the growth effects. A paper by Rytchkov (2010) tested the return predictability as to the US growth- and value-style portfolios. This paper found that the returns of the US growth- and value-style portfolios were forecastable, and for growth-style portfolios, the forecastability was more significant. Further, Larsen and Munk (2012) examined the effectiveness of the growth-value style tilting strategies in the framework of the dynamic asset allocation, and they advocated that such growth-value tilting strategies were highly effective. It is understood that in the existing literature, as the above literature review shows, the issues of international equity market interdependence and the value and growth effects on stock performances have been separately studied. Hence, again in this paper, we conduct new research that takes into consideration these two interesting issues.

\section{Data}

We next describe the data analyzed in this research. This paper uses four sorts of Japanese stock index return data and three kinds of US stock index return data. Specifically, plnk means the daily percentage log return of the Nikkei in Japan and pltpx means the daily percentage log return of the TOPIX in Japan. Further, pljg is the daily percentage $\log$ return of the MSCI Japanese growth-style equity index and pljv denotes the daily percentage log return of the MSCI Japanese value-style equity index. In addition, plus represents the daily percentage log return of the MSCI US standard equity index, plusg is the daily percentage log return of the MSCI US growth-style stock index, and plusv is the daily percentage log return of the MSCI US value-style stock index. In this research, our sample period is from 1 January 2009 to 8 April 2016 and the number of the time-series observations is 1897. All data used in this study are obtained from the Thomson Reuters.

Figure 1 shows the time-series return evolution of US and Japanese stock indices after the Lehman bankruptcy and the descriptive statistics of the above return data in the period are exhibited in Table 1. Table 1 suggests the following data characteristics. (1) First, the mean and median values are slightly positive for all stock index return data. (2) Next, Japanese stock index returns show somewhat higher volatilities than the US equity index returns. (3) Further, the values of skewness are slightly negative for all index return data.

\section{Methodology}

To test the dynamic effects of several Japanese stock index return evolution on the MSCI value, growth, and standard equity index returns in the US, this paper employs a univariate-GARCH model, in which the mean equation has the autoregressive (AR) terms. Namely, in this study, we use the following AR(5)-TGARCH(1,1) model to examine the time-varying effects of Japanese stock index returns on the three different US equity index return evolution:

$$
\begin{aligned}
& y_{t}=\eta_{1}+\eta_{2} z_{t}+\sum_{p=1}^{5} \lambda_{p} y_{t-p}+\varepsilon_{t}, \\
& \sigma_{t}^{2}=\psi_{1}+\psi_{2} \sigma_{t-1}^{2}+\psi_{3} \varepsilon_{t-1}^{2}+\psi_{4} \varepsilon_{t-1}^{2} d_{t-1},
\end{aligned}
$$

where $z_{t}$ is one of the stock index returns in Japan and $y_{t}$ is one of the stock index returns in the US. Further, $d_{t-1}=1$ 
if $\varepsilon_{t-1}<0$ and zero otherwise. Using this AR-TGARCH specification (1), we investigate the international dynamic effects of the Japanese stock returns of the Nikkei, TOPIX, and MSCI value- and growth-style equity indices on the MSCI US standard-, value-, and growth-style stock index returns. We note that between Tokyo and New York, there is 13- or 14-hour time difference and therefore, the Japanese stock market precedes the US equity market. Thus, we use the same-day return data of the US and Japanese stock price indices; and this enables us to evaluate the time-varying effects of the different kinds of Japanese stock indices on the different kinds of succeeding US stock index price changes.

Panel A. plnk

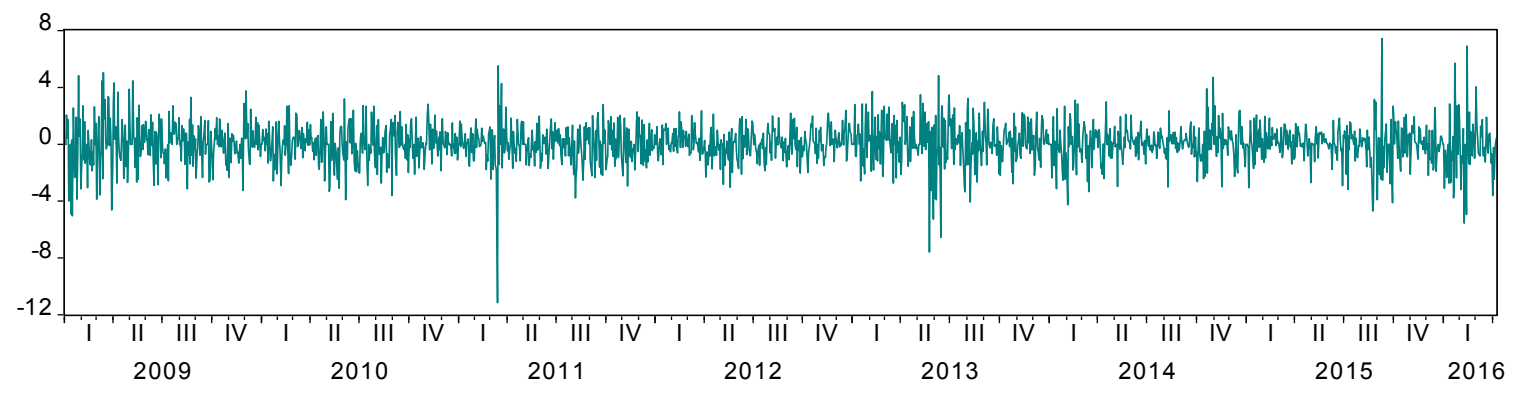

Panel B. pltpx

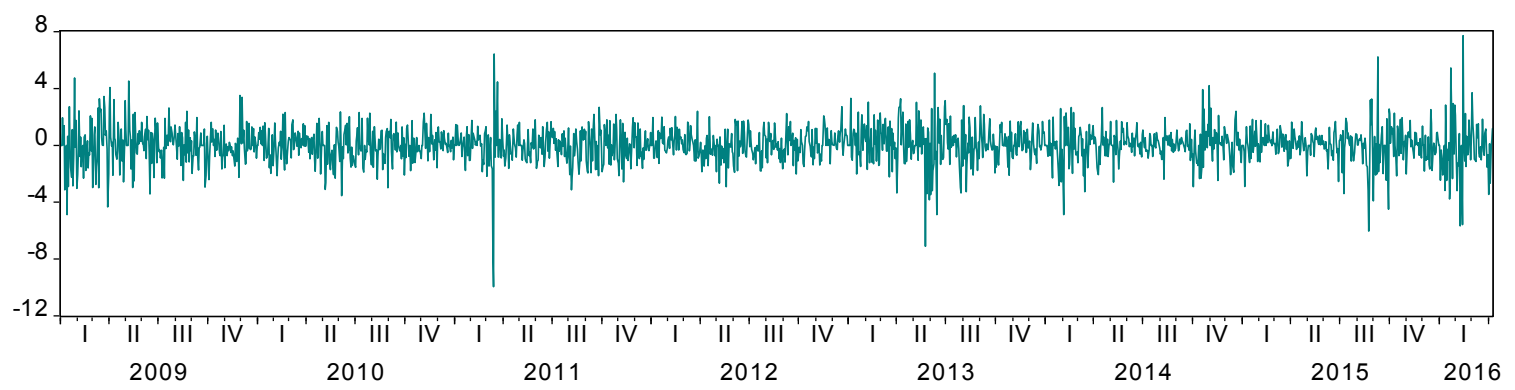

Panel C.pljg

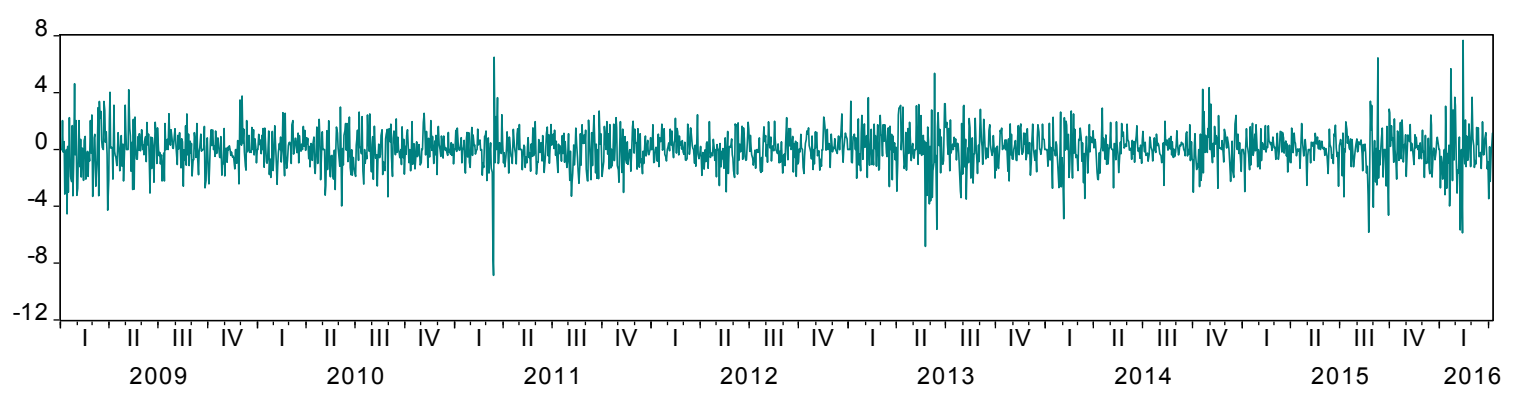

Panel D. pljv

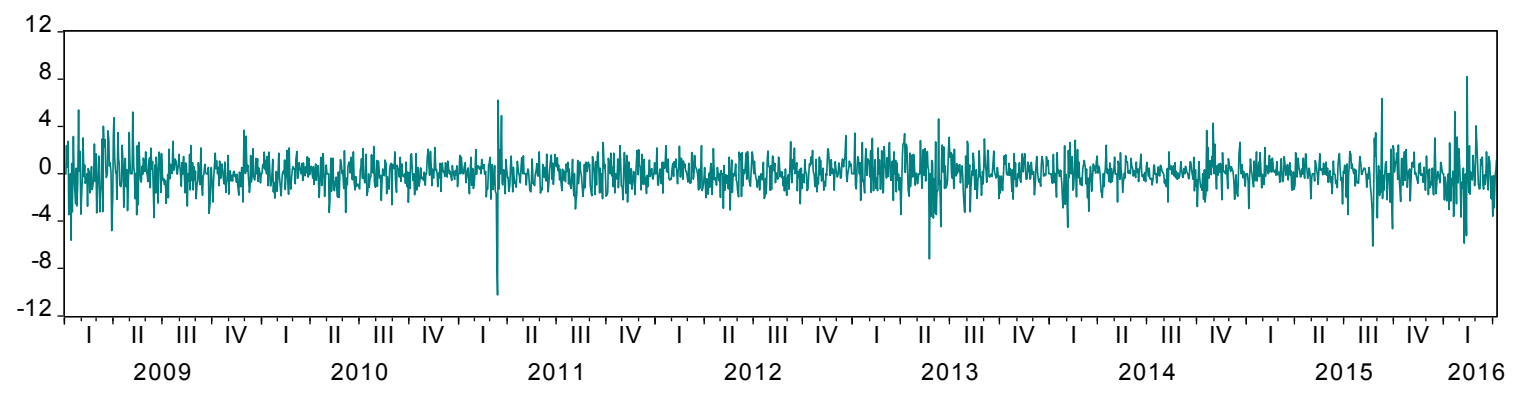


Panel E. plus

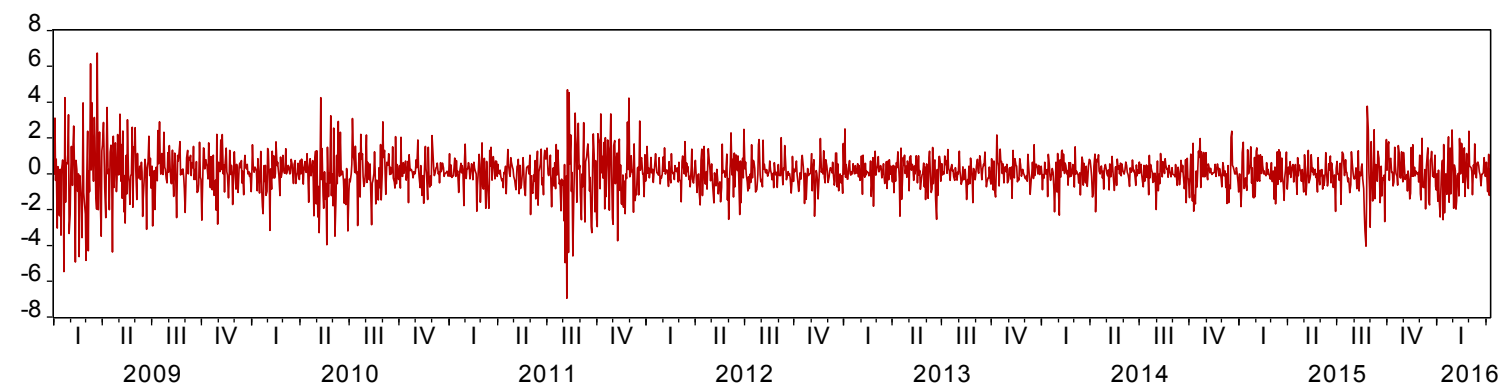

Panel F. plusg

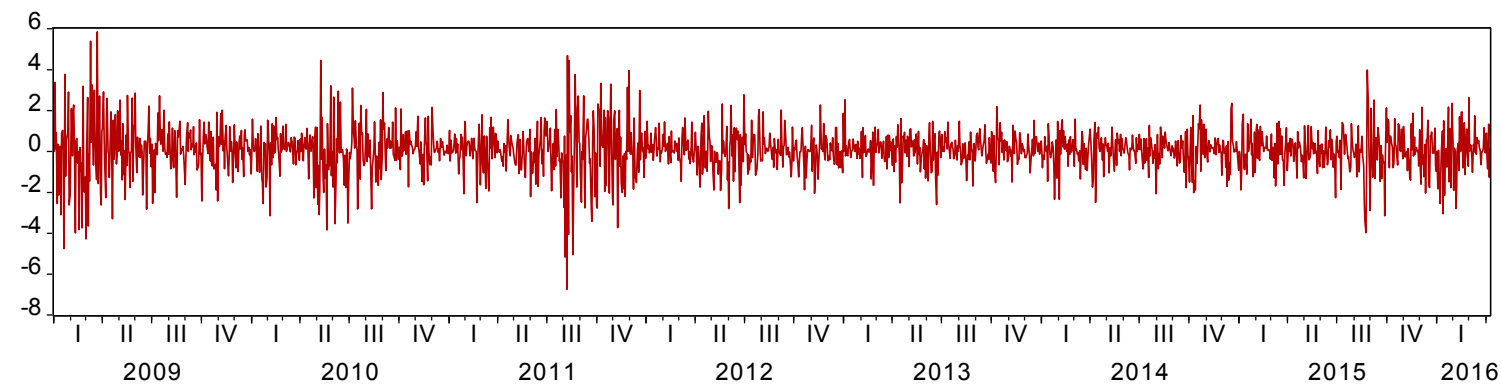

Panel G. plusv

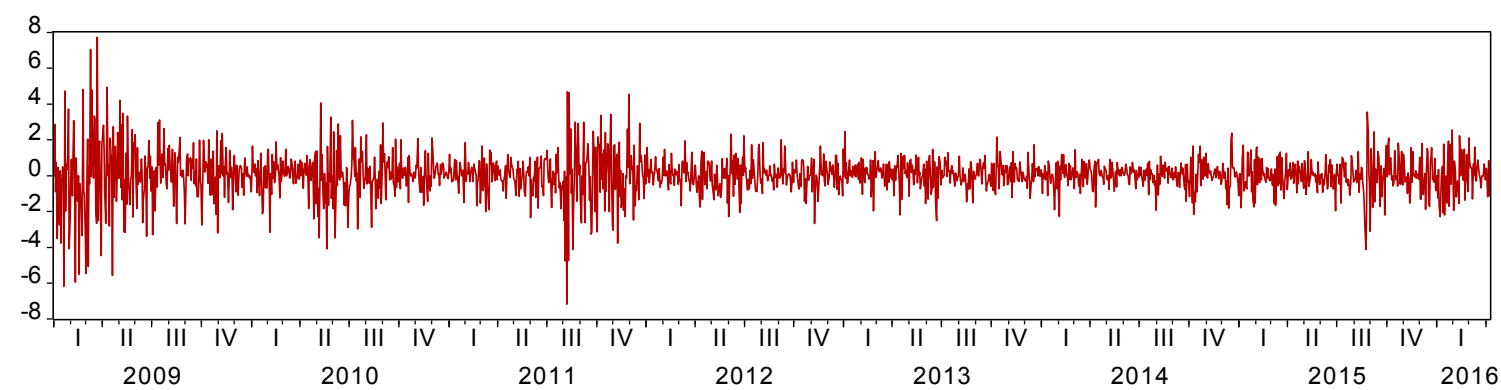

Figure 1. Time-series Evolution of US and Japanese Stock Index Returns after the Lehman Bankruptcy

\section{Empirical Results}

We here document the results of our empirical analyses. First, Tables 2 and 3 display the estimation results of our AR(5)-TGARCH(1,1) model (1) by using the Nikkei 225 and TOPIX as explanatory variables, respectively. Namely, Table 2 displays the dynamic effects of the Nikkei on the US three kinds of equity indices and Table 3 presents those of the TOPIX on the US three kinds of equity indices. Describing the key results, both in Tables 2 and 3, all coefficients of the daily log returns of the Nikkei and TOPIX are statistically significant with positive signs. Therefore, these results derived from our AR-TGARCH models indicate that the dynamic evolution of the Nikkei and TOPIX positively affects the following changes of standard-, growth-, and value-style equity indices in the US. In addition, in Table 2, we find the smallest values of both the Akaike's information criterion (hereinafter called 'AIC') and the Schwartz criterion (hereinafter called 'SC') in Panel A; and in Table 3, we also find the smallest values of both AIC and SC in Panel A. Hence, these results suggest that the Nikkei and TOPIX have the most substantial effect on the following changes of the US standard equity index. According to the above interesting results, we understand that the preceding Japanese representative stock price index returns of the Nikkei and TOPIX most significantly and robustly affect the succeeding US standard equity index price changes.

Furthermore, Tables 4 and 5 also display the estimation results of our AR(5)-TGARCH(1,1) model (1): Table 4 shows the dynamic effects of the Japanese growth index and Table 5 exhibits those of the Japanese value index, 
respectively. Both in Tables 4 and 5, all coefficients of the daily log returns of the Japanese growth and value indices are statistically significant with positive signs. Hence, these results from our AR-TGARCH models indicate that again, the preceding evolution of the Japanese growth and value stocks strongly affect the succeeding time-series of not only growth and value stock indices but also the standard stock index in the US. Moreover, in Table 4, the smallest values of both AIC and SC are found in Panel A. Thus, Table 4 shows that the Japanese growth index has the strongest influence on the standard stock index in the US. Further, in Table 5, we also find the smallest values of both AIC and SC in Panel A. Thus, these results again indicate that the Japanese value index movements have the strongest effect on the succeeding evolution of the US standard stock index. Hence, as the above results consistently demonstrate, it is very robust that the dynamic evolution of all the Japanese standard, value, and growth stock indices most strongly affects the standard stock index in the US. Therefore, our investigations reveal that after the Lehman bankruptcy in the US, the movements of all Japanese investment style indices are significantly important for the US standard equity index, namely, the US overall stock market.

Table 1. Descriptive Statistics for the Log Percentage Returns in Terms of the Nikkei, TOPIX, and MSCI Equity Indices for the US and Japan: For the Daily Sample Period from 1 January 2009 to 8 April 2016

\begin{tabular}{|c|c|c|c|c|}
\hline \multicolumn{5}{|c|}{ Nikkei and TOPIX } \\
\hline & \multicolumn{2}{|l|}{ plnk } & \multicolumn{2}{|l|}{ pltpx } \\
\hline Mean & \multicolumn{2}{|l|}{0.0306} & \multicolumn{2}{|l|}{0.0213} \\
\hline Median & \multicolumn{2}{|l|}{0.0000} & \multicolumn{2}{|l|}{0.0000} \\
\hline Maximum & \multicolumn{2}{|l|}{7.4262} & \multicolumn{2}{|l|}{7.7153} \\
\hline Minimum & \multicolumn{2}{|l|}{-11.1534} & \multicolumn{2}{|l|}{-9.9519} \\
\hline Standard deviation & \multicolumn{2}{|l|}{1.4233} & \multicolumn{2}{|l|}{1.3129} \\
\hline Skewness & \multicolumn{2}{|l|}{-0.4049} & \multicolumn{2}{|l|}{-0.3916} \\
\hline Kurtosis & \multicolumn{2}{|l|}{7.1707} & \multicolumn{2}{|l|}{7.9103} \\
\hline Observations & \multicolumn{2}{|l|}{1897} & \multicolumn{2}{|l|}{1897} \\
\hline \multicolumn{5}{|l|}{ MSCI indices } \\
\hline & \multicolumn{2}{|l|}{ pljg } & \multicolumn{2}{|l|}{ pljv } \\
\hline Mean & \multicolumn{2}{|l|}{0.0235} & \multicolumn{2}{|l|}{0.0162} \\
\hline Median & \multicolumn{2}{|l|}{0.0000} & \multicolumn{2}{|l|}{0.0000} \\
\hline Maximum & \multicolumn{2}{|l|}{7.6655} & \multicolumn{2}{|l|}{8.2081} \\
\hline Minimum & \multicolumn{2}{|l|}{-8.8734} & \multicolumn{2}{|l|}{-10.2408} \\
\hline Standard deviation & \multicolumn{2}{|l|}{1.3543} & 1.3471 & \\
\hline Skewness & -0.2655 & & -0.3171 & \\
\hline Kurtosis & 6.7078 & & 7.8924 & \\
\hline Observations & 1897 & & 1897 & \\
\hline Panel B. Statistics f & stock indi & & & \\
\hline MSCI indices & & & & \\
\hline & plus & plusg & & plusv \\
\hline Mean & 0.0434 & 0.0533 & & 0.0332 \\
\hline Median & 0.0412 & 0.0618 & & 0.0352 \\
\hline Maximum & 6.7347 & 5.8435 & & 7.7390 \\
\hline Minimum & -6.9601 & -6.7437 & & -7.1882 \\
\hline Standard deviation & 1.1131 & 1.0988 & & 1.1672 \\
\hline Skewness & -0.2778 & -0.2967 & & -0.2409 \\
\hline Kurtosis & 7.5133 & 6.5564 & & 8.7233 \\
\hline Observations & 1897 & 1897 & & 1897 \\
\hline
\end{tabular}

Notes: This table shows the descriptive statistics as to the daily percentage log returns of seven kinds of stock indices. The indices for Japan include the Nikkei 225 stock index, TOPIX, and MSCI Japanese growth and value stock indices; while the indices for the US include MSCI US standard, growth, and value stock indices. The sample period analyzed in this paper spans 1 January 2009 to 8 April 2016. 
Table 2. Dynamic Effects of the Nikkei 225 on Different US Stock Indices: Estimation Results of the AR-TGARCH Models with the GED Errors

Panel A. Effects of the Nikkei 225 on the US standard index

Estimation results in terms of mean equation and model statistics

\begin{tabular}{|c|c|c|c|c|}
\hline Variables & Coefficients & & $p$-value & \\
\hline Intercept & $0.0437 * * *$ & & 0.0043 & \\
\hline plnk & $0.0831^{* * *}$ & & 0.0000 & \\
\hline $\operatorname{AR}(1)$ & $-0.0910^{* * *}$ & & 0.0003 & \\
\hline $\operatorname{AR}(2)$ & -0.0047 & & 0.8308 & \\
\hline $\operatorname{AR}(3)$ & -0.0117 & & 0.5825 & \\
\hline $\mathrm{AR}(4)$ & 0.0094 & & 0.6605 & \\
\hline $\operatorname{AR}(5)$ & -0.0070 & & 0.7310 & \\
\hline $\mathrm{AIC}$ & 2.599877 & $\mathrm{SC}$ & & 2.635049 \\
\hline
\end{tabular}

Panel B. Effects of the Nikkei 225 on the US growth index

Estimation results in terms of mean equation and model statistics

\begin{tabular}{|c|c|c|}
\hline Variables & Coefficients & $p$-value \\
\hline Intercept & $0.0567 * * *$ & 0.0004 \\
\hline$p \operatorname{lnk}$ & $0.0819 * * *$ & 0.0000 \\
\hline $\operatorname{AR}(1)$ & $-0.0750 * * *$ & 0.0023 \\
\hline $\operatorname{AR}(2)$ & -0.0140 & 0.5209 \\
\hline $\operatorname{AR}(3)$ & -0.0196 & 0.3574 \\
\hline $\mathrm{AR}(4)$ & 0.0090 & 0.6740 \\
\hline $\operatorname{AR}(5)$ & 0.0054 & 0.7873 \\
\hline $\mathrm{AIC}$ & 2.644313 & 2.679485 \\
\hline
\end{tabular}

Panel C. Effects of the Nikkei 225 on the US value index

Estimation results in terms of mean equation and model statistics

\begin{tabular}{|c|c|c|c|}
\hline Variables & Coefficients & & $p$-value \\
\hline Intercept & $0.0340 * *$ & & 0.0261 \\
\hline$p \operatorname{lnk}$ & $0.0883^{* * *}$ & & 0.0000 \\
\hline $\operatorname{AR}(1)$ & $-0.1064 * * *$ & & 0.0001 \\
\hline $\operatorname{AR}(2)$ & -0.0067 & & 0.7699 \\
\hline $\operatorname{AR}(3)$ & -0.0034 & & 0.8785 \\
\hline $\mathrm{AR}(4)$ & -0.0015 & & 0.9483 \\
\hline $\mathrm{AR}(5)$ & -0.0178 & & 0.4072 \\
\hline AIC & 2.634255 & $\mathrm{SC}$ & 2.669426 \\
\hline
\end{tabular}

Notes: The Akaike's information criterion is denoted by AIC and the Schwartz criterion is denoted by SC. ***, **, and $*$ denote the statistical significance at the 1,5 , and $10 \%$ levels, respectively. 
Table 3. Dynamic Effects of the TOPIX on Different US Stock Indices: Estimation Results of the AR-TGARCH Models with the GED Errors

Panel A. Effects of the TOPIX on the US standard index

Estimation results in terms of mean equation and model statistics

\begin{tabular}{|c|c|c|}
\hline Variables & Coefficients & $p$-value \\
\hline Intercept & $0.0451 * * *$ & 0.0030 \\
\hline pltpx & $0.0852 * * *$ & 0.0000 \\
\hline $\mathrm{AR}(1)$ & $-0.0861 * * *$ & 0.0005 \\
\hline $\operatorname{AR}(2)$ & -0.0118 & 0.5902 \\
\hline $\operatorname{AR}(3)$ & -0.0130 & 0.5383 \\
\hline $\operatorname{AR}(4)$ & 0.0085 & 0.6897 \\
\hline $\mathrm{AR}(5)$ & -0.0044 & 0.8299 \\
\hline AIC & 2.601072 & 2.636243 \\
\hline
\end{tabular}

Panel B. Effects of the TOPIX on the US growth index

Estimation results in terms of mean equation and model statistics

\begin{tabular}{|c|c|c|}
\hline Variables & Coefficients & $p$-value \\
\hline Intercept & $0.0602 * * *$ & 0.0001 \\
\hline pltpx & $0.0804 * * *$ & 0.0000 \\
\hline $\mathrm{AR}(1)$ & $-0.0683 * * *$ & 0.0048 \\
\hline $\mathrm{AR}(2)$ & -0.0190 & 0.3816 \\
\hline $\operatorname{AR}(3)$ & -0.0190 & 0.3687 \\
\hline $\mathrm{AR}(4)$ & 0.0064 & 0.7614 \\
\hline $\operatorname{AR}(5)$ & 0.0104 & 0.6037 \\
\hline AIC & 2.645426 & 2.680598 \\
\hline
\end{tabular}

Panel C. Effects of the TOPIX on the US value index

Estimation results in terms of mean equation and model statistics

\begin{tabular}{|c|c|c|}
\hline Variables & Coefficients & $p$-value \\
\hline Intercept & $0.0358 * *$ & 0.0196 \\
\hline pltpx & $0.0910 * * *$ & 0.0000 \\
\hline $\operatorname{AR}(1)$ & $-0.1006^{* * *}$ & 0.0001 \\
\hline $\mathrm{AR}(2)$ & -0.0107 & 0.6373 \\
\hline $\operatorname{AR}(3)$ & -0.0028 & 0.8985 \\
\hline $\mathrm{AR}(4)$ & -0.0011 & 0.9600 \\
\hline $\operatorname{AR}(5)$ & -0.0158 & 0.4611 \\
\hline AIC & 2.635274 & 2.670445 \\
\hline
\end{tabular}

Notes: The Akaike's information criterion is denoted by AIC and the Schwartz criterion is denoted by SC. ***, **, and $*$ denote the statistical significance at the 1,5 , and $10 \%$ levels, respectively. 
Table 4. Dynamic Effects of the Japanese Growth Stock Index on Different US Stock Indices: Estimation Results of the AR-TGARCH Models with the GED Errors

Panel A. Effects of the Japanese growth index on the US standard index

Estimation results in terms of mean equation and model statistics

\begin{tabular}{|c|c|c|c|c|}
\hline Variables & Coefficients & & $p$-value & \\
\hline Intercept & $0.0451 * * *$ & & 0.0031 & \\
\hline pljg & $0.0859 * * *$ & & 0.0000 & \\
\hline $\operatorname{AR}(1)$ & $-0.0879 * * *$ & & 0.0004 & \\
\hline $\operatorname{AR}(2)$ & -0.0089 & & 0.6846 & \\
\hline $\operatorname{AR}(3)$ & -0.0132 & & 0.5320 & \\
\hline $\operatorname{AR}(4)$ & 0.0099 & & 0.6423 & \\
\hline $\operatorname{AR}(5)$ & -0.0052 & & 0.7983 & \\
\hline AIC & 2.599831 & $\mathrm{SC}$ & & 2.635003 \\
\hline
\end{tabular}

Panel B. Effects of the Japanese growth index on the US growth index

Estimation results in terms of mean equation and model statistics

\begin{tabular}{|c|c|c|c|c|}
\hline Variables & Coefficients & & $p$-value & \\
\hline Intercept & $0.0582 * * *$ & & 0.0002 & \\
\hline pljg & $0.0850 * * *$ & & 0.0000 & \\
\hline $\operatorname{AR}(1)$ & $-0.0714 * * *$ & & 0.0032 & \\
\hline $\operatorname{AR}(2)$ & -0.0174 & & 0.4227 & \\
\hline $\operatorname{AR}(3)$ & -0.0199 & & 0.3487 & \\
\hline $\operatorname{AR}(4)$ & 0.0075 & & 0.7238 & \\
\hline $\operatorname{AR}(5)$ & 0.0080 & & 0.6917 & \\
\hline AIC & 2.643213 & $\mathrm{SC}$ & & 2.678384 \\
\hline
\end{tabular}

Panel C. Effects of the Japanese growth index on the US value index

Estimation results in terms of mean equation and model statistics

\begin{tabular}{|c|c|c|c|}
\hline Variables & Coefficients & & $p$-value \\
\hline Intercept & $0.0348 * *$ & & 0.0230 \\
\hline pljg & $0.0900 * * *$ & & 0.0000 \\
\hline $\operatorname{AR}(1)$ & $-0.1013 * * *$ & & 0.0001 \\
\hline $\operatorname{AR}(2)$ & -0.0098 & & 0.6655 \\
\hline $\operatorname{AR}(3)$ & -0.0042 & & 0.8480 \\
\hline $\operatorname{AR}(4)$ & -0.0016 & & 0.9439 \\
\hline $\operatorname{AR}(5)$ & -0.0166 & & 0.4387 \\
\hline AIC & 2.634584 & $\mathrm{SC}$ & 2.669756 \\
\hline
\end{tabular}

Notes: The Akaike's information criterion is denoted by AIC and the Schwartz criterion is denoted by SC. ***, **, and $*$ denote the statistical significance at the 1,5 , and $10 \%$ levels, respectively. 
Table 5. Dynamic Effects of the Japanese Value Stock Index on Different US Stock Indices: Estimation Results of the AR-TGARCH Models with the GED Errors

\begin{tabular}{|c|c|c|}
\hline \multicolumn{3}{|c|}{ Estimation results in terms of mean equation and model statistics } \\
\hline Variables & Coefficients & $p$-value \\
\hline Intercept & $0.0472 * * *$ & 0.0018 \\
\hline pljv & $0.0828 * * *$ & 0.0000 \\
\hline $\operatorname{AR}(1)$ & $-0.0863 * * *$ & 0.0005 \\
\hline $\operatorname{AR}(2)$ & -0.0128 & 0.5586 \\
\hline $\operatorname{AR}(3)$ & -0.0109 & 0.6046 \\
\hline $\operatorname{AR}(4)$ & 0.0070 & 0.7415 \\
\hline $\operatorname{AR}(5)$ & -0.0044 & 0.8281 \\
\hline AIC & 2.600802 & 2.635973 \\
\hline
\end{tabular}

Panel B. Effects of the Japanese value index on the US growth index

Estimation results in terms of mean equation and model statistics

\begin{tabular}{|c|c|c|c|c|}
\hline Variables & Coefficients & & $p$-value & \\
\hline Intercept & $0.0593 * * *$ & & 0.0002 & \\
\hline pljv & $0.0758 * * *$ & & 0.0000 & \\
\hline $\operatorname{AR}(1)$ & $-0.0654 * * *$ & & 0.0068 & \\
\hline $\operatorname{AR}(2)$ & -0.0190 & & 0.3815 & \\
\hline $\operatorname{AR}(3)$ & -0.0161 & & 0.4446 & \\
\hline $\operatorname{AR}(4)$ & 0.0061 & & 0.7724 & \\
\hline $\operatorname{AR}(5)$ & 0.0104 & & 0.6044 & \\
\hline AIC & 2.646214 & $\mathrm{SC}$ & & 2.681386 \\
\hline
\end{tabular}

Panel C. Effects of the Japanese value index on the US value index

Estimation results in terms of mean equation and model statistics

\begin{tabular}{|c|c|c|c|c|}
\hline Variables & Coefficients & & $p$-value & \\
\hline Intercept & $0.0367 * *$ & & 0.0160 & \\
\hline$p l j v$ & $0.0918 * * *$ & & 0.0000 & \\
\hline $\operatorname{AR}(1)$ & $-0.1039 * * *$ & & 0.0001 & \\
\hline $\operatorname{AR}(2)$ & -0.0129 & & 0.5704 & \\
\hline $\operatorname{AR}(3)$ & 0.0002 & & 0.9928 & \\
\hline $\operatorname{AR}(4)$ & -0.0013 & & 0.9528 & \\
\hline $\operatorname{AR}(5)$ & -0.0156 & & 0.4678 & \\
\hline AIC & 2.634323 & $\mathrm{SC}$ & & 2.669495 \\
\hline
\end{tabular}

Notes: The Akaike's information criterion is denoted by AIC and the Schwartz criterion is denoted by SC. ***, **, and $*$ denote the statistical significance at the 1,5 , and $10 \%$ levels, respectively. 


\section{Conclusions}

In this paper, for clarifying the stock return relations of Japanese investment styles and US investment styles after the Lehman bankruptcy in the US, we empirically explored the dynamic return linkages of Japanese four kinds of stock indices and US three kinds of stock indices. Specifically, this study empirically inspected the dynamic effects of the Nikkei 225, TOPIX, and the MSCI Japanese value- and growth-style stock indices on the MSCI standard-, value-, and growth-style stock indices in the US. As a result of our analyses with AR-TGARCH models, we obtained clear and consistent interesting findings as follows.

(1) First, our examinations by AR-TGARCH models evidenced that after the Lehman bankruptcy in the US, the Nikkei and TOPIX had a stronger effect on the MSCI US standard stock index than on the MSCI value- and growth-style indices in the US. (2) Second, our explorations by the AR-TGARCH models further revealed that after the Lehman bankruptcy in the US, the time-series evolution of the MSCI Japanese value and growth indices also more strongly influenced the MSCI US standard stock index than the MSCI US value- and growth-style stock indices. To sum up, after the Lehman bankruptcy in the US, our investigations revealed that all Japanese investment style indices were important for the US overall stock market.

We consider that it is interesting and surprising that not the same sorts of stock indices but the different kinds of stock indices of the US and Japan exhibited stronger dynamic relations; and as our study demonstrated, these were robustly evidenced in the period after the collapse of Lehman Brothers in the US. Furthermore, it is also noted that our new analyzing approach to different types of equity indices in two international markets shall bring some additional new viewpoints to future research of international stock market interdependence. Further research by using other combinations of different international stock indices with different analyzing viewpoints from previous studies is also our future works; and this line of research may derive further new findings and useful practical implications in this field.

\section{Acknowledgements}

I am particularly grateful to the repeated kind article invitation from this journal. I also appreciate the Zengin Foundation for Studies on Economics and Finance for their grant-in-aid to this research. Moreover, I thank the anonymous referees for their kind and supportive comments on this paper, and I also thank Monica Anderson for her kind editorial assistance to my paper. Furthermore, I deeply thank all the Editors of this journal for their kindness to my paper.

\section{References}

Abhyankar, A., Ho, K. Y., \& Zhao, H. (2009). International value versus growth: Evidence from stochastic dominance analysis. International Journal of Finance \& Economics, 14, 222-232. http://dx.doi.org/10.1002/ijfe.368

Black, A. J., Fraser, P., \& McMillan, D. G. (2007). Are international value premiums driven by the same set of fundamentals? International Review of Economics and Finance, 16, 113-129. http://dx.doi.org/10.1016/j.iref.2005.05.002

Ding, D. K., Chua, J. L., \& Fetherston, T. A. (2005). The performance of value and growth portfolios in East Asia before the Asian financial crisis. Pacific-Basin Finance Journal, 13, 185-199. http://dx.doi.org/10.1016/j.pacfin.2004.07.001

el Alaoui, A. O., Dewandaru, G., Rosly, S. A., \& Masih, M. (2015). Linkages and co-movement between international stock market returns: Case of Dow Jones Islamic Dubai financial market index. Journal of International Financial Markets, Institutions and Money, 36, 53-70. http://dx.doi.org/10.1016/j.intfin.2014.12.004

Fama, E. F., \& French, K. R. (2007). The anatomy of value and growth stock returns. Financial Analysts Journal, 63, 44-54. http://dx.doi.org/10.2469/faj.v63.n6.4926

Fama, E. F., \& French, K. R. (2012). Size, value, and momentum in international stock returns. Journal of Financial Economics, 105, 457-472. http://dx.doi.org/10.1016/j.jfineco.2012.05.011

Graham, M., Kiviaho, J., Nikkinen, J., \& Omran, M. (2013). Global and regional co-movement of the MENA stock markets. Journal of Economics and Business, 65, 86-100. http://dx.doi.org/10.1016/j.jeconbus.2012.09.005 
Gupta, R., \& Guidi, F. (2012). Cointegration relationship and time varying co-movements among Indian and Asian developed stock markets. International Review of Financial Analysis, 21, 10-22. http://dx.doi.org/10.1016/j.irfa.2011.09.001

Huang, I. H. (2011). The cyclical behavior of the risk of value strategy: Evidence from Taiwan. Pacific-Basin Finance Journal, 19, 404-419. http://dx.doi.org/10.1016/j.pacfin.2011.03.002

Larsen, L. S., \& Munk, C. (2012). The costs of suboptimal dynamic asset allocation: General results and applications to interest rate risk, stock volatility risk, and growth/value tilts. Journal of Economic Dynamics \& Control, 36, 266-293. http://dx.doi.org/10.1016/j.jedc.2011.09.009

Liu, L. (2013). International stock market interdependence: Are developing markets the same as developed markets? Journal of International Financial Markets, Institutions \& Money, 26, 226-238. http://dx.doi.org/10.1016/j.intfin.2013.06.003

Rytchkov, O. (2010). Expected returns on value, growth, and HML. Journal of Empirical Finance, 17, 552-565. http://dx.doi.org/10.1016/j.jempfin.2010.04.003

Voronkova, S. (2004). Equity market integration in Central European emerging markets: A cointegration analysis with shifting regimes. International Review of Financial Analysis, 13, 633-647. http://dx.doi.org/10.1016/j.irfa.2004.02.017

Wälti, S. (2011). Stock market synchronization and monetary integration. Journal of International Money and Finance, 30, 96-110. http://dx.doi.org/10.1016/j.jimonfin.2010.07.004 